Article

\title{
Molecularly Imprinted Polymers Based Electrochemical Sensor for 2,4-Dichlorophenol Determination
}

\author{
Benzhi Liu *, Hui Cang and Jianxiang Jin \\ School of Environmental Science and Engineering, Yancheng Institute of Technology, 224051 Yancheng, China; \\ canghui@ycit.edu.cn (H.C.); ygjjx2000@163.com (J.J.) \\ * Correspondence: lbzycit@163.com; Tel.: +86-515-8829-8806; Fax: +86-515-8829-8805 \\ Academic Editor: Shiyong Liu \\ Received: 30 June 2016; Accepted: 12 August 2016; Published: 18 August 2016
}

\begin{abstract}
A molecularly imprinted polymers based electrochemical sensor was fabricated by electropolymerizing pyrrole on a $\mathrm{Fe}_{3} \mathrm{O}_{4}$ nanoparticle modified glassy carbon electrode. The sensor showed highly catalytic ability for the oxidation of 2,4-dichlorophenol (2,4-DCP). Square wave voltammetry was used for the determination of 2,4-DCP. The oxidation peak currents were proportional to the concentrations of 2,4-DCP in the range of 0.04 to $2.0 \mu \mathrm{M}$, with a detection limit of $0.01 \mu \mathrm{M}$. The proposed sensor was successfully applied for the determination of 2,4-DCP in water samples giving satisfactory recoveries.
\end{abstract}

Keywords: 2,4-dichlorophenol; electrochemical sensor; molecularly imprinted polymers

\section{Introduction}

The chemical 2,4-dichlorophenol (2,4-DCP) is representative of chlorophenol compounds. It is widely used in the manufacture of some phenoxy herbicides, insecticides, and pharmaceuticals but poses remarkable environmental risks to human health due to its high toxicity, persistence in the environment, and suspected carcinogenic properties [1]. As a consequence, the US Environmental Protection Agency and European Union have listed it as a priority pollutant. Thus, the development of sensitive, simple and accurate analytical methods is required for the determination of 2,4-DCP. Many analytical methods including high performance liquid chromatography [2], gas chromatography [3], chemiluminescence [4], and electrochemical methods [5-8] have been developed to detect 2,4-DCP. Among them, electrochemical methods have some advantages for their high sensitivity, simple operation, rapid response, and small size that afford a portable sensor for on-site detection.

Recently, molecularly imprinted polymers (MIPs) based electrochemical sensors have received considerable attention due to their high selectivity and sensitivity [9-11]. In electrochemical sensors, MIPs can not only accumulate template molecules on the electrode surface to enhance the sensitivity, but also separate template molecules from the other analytes to improve the selectivity. For the preparation of MIPs, electropolymerization is a simple method which can directly prepare rigid, uniform, and compact MIPs film on the electrode surface [12]. Moreover, MIPs film prepared by electropolymerization has high stability, electrocatalytic activity, and conductivity, which could improve the sensitivity and selectivity of sensors. However, fewer imprinted sites formed on the electrode surface due to the relatively high density of electropolymers [13]. Because of the large surface area, nanomaterial could also be used as a carrier in the preparation of MIPs to increase the number of imprinted cavities. In this work, $\mathrm{Fe}_{3} \mathrm{O}_{4}$ nanoparticles were prepared and immobilized on the surface of an electrode. The polymers could be electropolymerized on the surface of $\mathrm{Fe}_{3} \mathrm{O}_{4}$ nanoparticles. 
In recent years, $\mathrm{Fe}_{3} \mathrm{O}_{4}$ nanoparticles have attracted much interest in the fields of separation science, electrochemistry, and catalysis, etc. [14-16]. Because of the large surface area and catalytic performance of $\mathrm{Fe}_{3} \mathrm{O}_{4}$ nanoparticles, the number of imprinted cavities could be enhanced and the selectivity and sensitivity of the sensor could be improved.

As an electroactive functional monomer, pyrrole is often employed to fabricate MIPs sensors for recognition and detection of a variety of molecules [17-20]. In this work, a simple and efficient MIPs based electrochemical sensor was prepared by electropolymerization of pyrrole on a $\mathrm{Fe}_{3} \mathrm{O}_{4}$ nanoparticle modified glassy carbon electrode. The sensor showed high selectivity and sensitivity for the detection of 2,4-DCP.In addition, the proposed sensor has a wide linear range and a low detection limit, which makes it suitable for the determination of trace 2,4-DCP. Recovery experiments suggest promising applicability of the sensor for the direct determination of 2,4-DCP in real samples.

\section{Materials and Methods}

\subsection{Instrumentation and Reagents}

All electrochemical experiments were carried out on a CS350 Electrochemical Workstation (Wuhan Corrtest Instruments Co., Ltd., Wuhan, China). A conventional three-electrode cell configuration was employed for the electrochemical measurements. A modified glassy carbon electrode (disc diameter of $3 \mathrm{~mm}$ ) was used as the working electrode. The saturated calomel electrode (Saturated $\mathrm{KCl}$ ) and platinum wire were employed as the reference and the counter electrode, respectively. Scanning electron microscopy (SEM) images were obtained using S-3400N II (Hitachi, Tokyo, Japan).

Pyrrole, 2-chlorophenol, 2,4-dichlorophenol, 2,4,6-trichlorophenol, hydroquinol, and hydroxyphenol were purchased from Sinopharm Chemical Reagent Co., Ltd. (Beijing, China). All other chemical reagents (AR grade) were obtained from Nanjing Chemical Reagent Company (Nanjing, China). Stock solution of $5.0 \times 10^{-4} \mathrm{~mol} \cdot \mathrm{L}^{-1} 2,4-\mathrm{DCP}$ was prepared by dissolving 2,4-DCP in ethanol, and then diluting to working solution at the desired concentration.

\subsection{Fabrication of the Modified Electrodes}

$\mathrm{Fe}_{3} \mathrm{O}_{4}$ nanoparticles were synthesized according to the following procedure. $0.86 \mathrm{~g} \mathrm{FeCl}_{2} \cdot 4 \mathrm{H}_{2} \mathrm{O}$ and $2.36 \mathrm{~g} \mathrm{FeCl}_{3} \cdot 6 \mathrm{H}_{2} \mathrm{O}$ were dissolved in $40 \mathrm{~mL}$ water. The mixture was magnetically stirred and purged with nitrogen gas, and then $5 \mathrm{~mL}$ aqueous ammonia was added. The reaction was kept for $1 \mathrm{~h}$ at $80{ }^{\circ} \mathrm{C}$. After completion, the $\mathrm{Fe}_{3} \mathrm{O}_{4}$ nanoparticles were washed by deionized water until neutral. Then $0.1 \mathrm{~g}$ of neutral $\mathrm{Fe}_{3} \mathrm{O}_{4}$ nanoparticles were dispersed in $25 \mathrm{~mL}$ of methanol.

Subsequently, $8 \mu \mathrm{L} \mathrm{Fe}_{3} \mathrm{O}_{4}$ nanoparticles $\left(4 \mathrm{mg} \cdot \mathrm{mL}^{-1}\right)$ were dropped onto the surface of a cleaned glassy carbon electrode (GCE) and then dried in air to prepare $\mathrm{Fe}_{3} \mathrm{O}_{4} / \mathrm{GCE}$. For the preparation of MIPs $/ \mathrm{Fe}_{3} \mathrm{O}_{4} / \mathrm{GCE}$, the $\mathrm{Fe}_{3} \mathrm{O}_{4} / \mathrm{GCE}$ was incubated in a $0.1 \mathrm{~mol} \cdot \mathrm{L}^{-1}$ phosphate buffer solution (PBS) containing $6 \mathrm{mmol} \cdot \mathrm{L}^{-1}$ pyrrole, $5 \mathrm{mmol} \cdot \mathrm{L}^{-1} 2,4-\mathrm{DCP}$ and $0.1 \mathrm{~mol} \cdot \mathrm{L}^{-1} \mathrm{KCl}$ for $20 \mathrm{~min}$ at room temperature to complete the adsorption of 2,4-DCP and to pre-assemble between template and monomer. The electropolymerization was carried out using the cyclic voltammetry $(\mathrm{CV})$ method at a scan rate of $0.1 \mathrm{Vs}^{-1}$ between -0.2 and $+1.2 \mathrm{~V}$ for 20 cycles. Then, the embedded 2,4-DCP was removed by scanning between 0 and $+1.1 \mathrm{~V}$ in a $0.5 \mathrm{~mol} \mathrm{~L}{ }^{-1} \mathrm{KOH}$ and $0.1 \mathrm{~mol} \cdot \mathrm{L}^{-1} \mathrm{KCl}$ solution for several cycles until no obvious peak could be observed. The procedure for the preparation of $\mathrm{MIPs} / \mathrm{Fe}_{3} \mathrm{O}_{4} / \mathrm{GCE}$ is depicted in Figure 1.

As a control, a non-molecularly imprinted polymers (NIPs) modified electrode (NIPs $/ \mathrm{Fe}_{3} \mathrm{O}_{4} / \mathrm{GCE}$ ) was prepared and treated in the same manner except for the addition of 2,4-DCP. A GCE was used to prepare MIPs/GCE according to the preparation of MIPs/ $\mathrm{Fe}_{3} \mathrm{O}_{4} / \mathrm{GCE}$. 


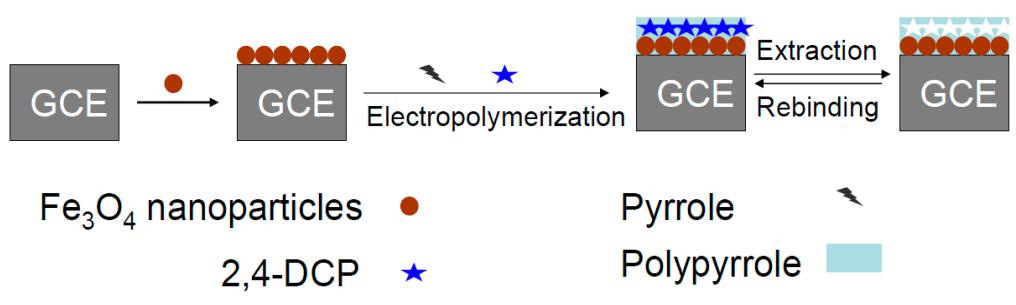

Figure 1. The procedure for the preparation of molecularly imprinted polymers modified glassy carbon electrode (MIPs $/ \mathrm{Fe}_{3} \mathrm{O}_{4} / \mathrm{GCE}$ ).

\subsection{Experimental Measurements}

The morphology of prepared $\mathrm{Fe}_{3} \mathrm{O}_{4}$ nanoparticles and MIPs $/ \mathrm{Fe}_{3} \mathrm{O}_{4}$ were observed by using scanning electron microscopy (SEM, S-3400N II). Electrochemical measurements were carried out according to the following procedure: A certain volume of 2,4-DCP stock solution and $10 \mathrm{~mL}$ of $0.1 \mathrm{~mol} \cdot \mathrm{L}^{-1} \mathrm{PBS}$ ( $\mathrm{pH}$ 6.0) were added to an electrochemical cell, and then a three electrode system was installed in it. After $120 \mathrm{~s}$ incubation, the cyclic voltammograms were recorded from 0.3 to $1.1 \mathrm{~V}$ at scan rate of $0.1 \mathrm{Vs}^{-1}$, the square wave voltammograms were recorded from 0.3 to $1.1 \mathrm{~V}$ with a step increment of $4 \mathrm{mV}$, amplitude of $25 \mathrm{mV}$, and frequency of $15 \mathrm{~Hz}$.

To investigate the applicability of the proposed sensor for the determination of 2,4-DCP, local river water samples were used for the quantitative analysis. An amount of $10 \mathrm{~mL}$ of the water sample was transferred to the cell containing $10 \mathrm{~mL}$ of $0.1 \mathrm{~mol} \cdot \mathrm{L}^{-1} \mathrm{PBS}(\mathrm{pH} 6.0)$ and detected by square wave voltammetry under optimal conditions. The recovery experiments were performed by adding 2,4-DCP with two concentration levels and each sample was determined three times under the same conditions by square wave voltammetry.

\section{Results and Discussion}

\subsection{Morphology of $\mathrm{Fe}_{3} \mathrm{O}_{4}$ Nanoparticles and $\mathrm{MIPS} / \mathrm{Fe}_{3} \mathrm{O}_{4}$}

The surface morphology of $\mathrm{Fe}_{3} \mathrm{O}_{4}$ nanoparticles and MIPs $/ \mathrm{Fe}_{3} \mathrm{O}_{4}$ were evaluated by SEM. As shown in Figure 2, $\mathrm{Fe}_{3} \mathrm{O}_{4}$ nanoparticles were uniformly dispersed without obvious aggregation (Figure 2A), the size of $\mathrm{Fe}_{3} \mathrm{O}_{4}$ nanoparticles was about $120 \mathrm{~nm}$. After electropolymerization, the surface became much rougher, indicating the deposition of polymers. The polymers seemed to be coated on the surface of the $\mathrm{Fe}_{3} \mathrm{O}_{4}$ nanoparticles (Figure 2B). As shown with the arrow in Figure 2C, a cauliflower-like polymer could be observed, but it is not obvious.
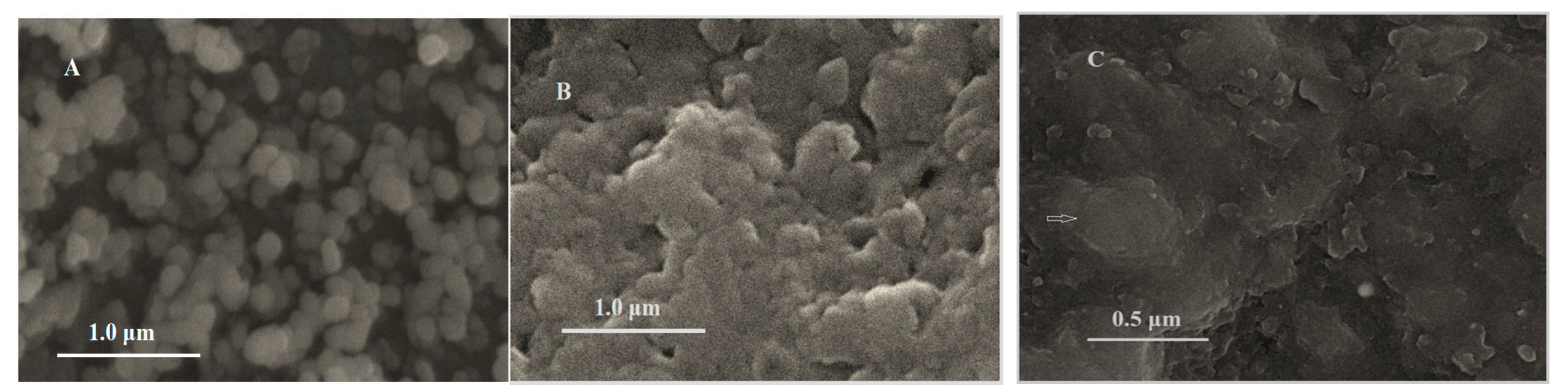

Figure 2. Scanning electron microscopy (SEM) images of (A) $\mathrm{Fe}_{3} \mathrm{O}_{4}$ nanoparticles; (B) $\mathrm{MIPs} / \mathrm{Fe}_{3} \mathrm{O}_{4}$; and $(\mathrm{C})$ high resolution of $\mathrm{MIPs} / \mathrm{Fe}_{3} \mathrm{O}_{4}$.

\subsection{Electrochemical Behavior of 2,4-DCP at Modified Electrodes}

Use of cyclic voltammograms is an effective tool for studying the electrochemical properties of the modified electrodes. Figure 3 shows the $\mathrm{CV}$ responses of different modified electrodes in 
$0.1 \mathrm{~mol} \cdot \mathrm{L}^{-1} \mathrm{PBS}$ containing $50 \mu \mathrm{M}$ of 2,4-DCP. As can be seen, no obvious peak is found for bare GCE. A poor oxidation peak could be observed on the $\mathrm{Fe}_{3} \mathrm{O}_{4} / \mathrm{GCE}$ due to the weak catalysis of $\mathrm{Fe}_{3} \mathrm{O}_{4}$. However, there is a well-defined oxidation peak on the MIPs/GCE, indicating that pyrrole could be used to prepare electropolymers and the polymers had high catalytic ability for the oxidation of 2,4-DCP. A large well-defined oxidation peak is observed on the MIPs $/ \mathrm{Fe}_{3} \mathrm{O}_{4} / \mathrm{GCE}$, the peak current is about 2.8 times that of NIPs $/ \mathrm{Fe}_{3} \mathrm{O}_{4} / \mathrm{GCE}$, which indicated that $\mathrm{MIPs} / \mathrm{Fe}_{3} \mathrm{O}_{4} / \mathrm{GCE}$ had high selectivity to the adsorption of 2,4-DCP.

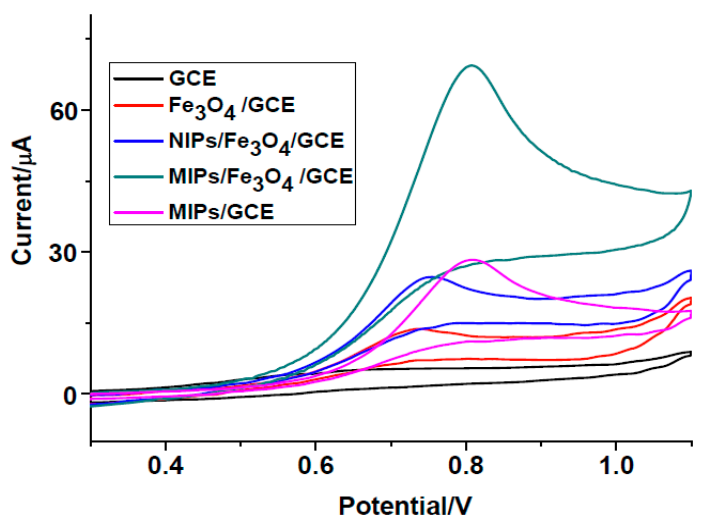

Figure 3. Cyclic voltammograms (CVs) of modified electrodes in $0.1 \mathrm{~mol} \cdot \mathrm{L}^{-1}$ phosphate buffer solution (PBS) containing $50 \mu \mathrm{M}$ of 2,4-DCP. Scan rate: $0.1 \mathrm{Vs}^{-1}$.

\subsection{Optimization of $\mathrm{MIPS} / \mathrm{Fe}_{3} \mathrm{O}_{4} / \mathrm{GCE}$ Preparation Conditions}

In order to fabricate a highly sensitive sensor, the influences of different preparation conditions including the amount of $\mathrm{Fe}_{3} \mathrm{O}_{4}$ nanoparticles, the ratio of template/monomer, electropolymerization scan cycles and scan rate on the response of the sensor to $20 \mu \mathrm{M}$ of 2,4-DCP were investigated.

In this work, $\mathrm{Fe}_{3} \mathrm{O}_{4}$ nanoparticles were used to enhance the immobilized amounts of imprinted cavities for adsorption of templates. It can be seen that the highest peak current was obtained for $8 \mu \mathrm{L}$ of the prepared $\mathrm{Fe}_{3} \mathrm{O}_{4}$ nanoparticles (Figure $4 \mathrm{~A}$ ). In the electrodeposition of MIPs, the ratio of template/monomer could influence the amount of template molecules embedded in the polymer matrix. The results suggested that the template/monomer ratio of 5:6 exhibited the highest peak current for the sensor (Figure 4B).

The thickness of the MIPs was another important parameter that affected the sensitivity and selectivity of the sensor. Although greater deposition of templates leads to a higher number of imprinted sites, it is difficult to remove the template completely from excessively thick polymers, which lead to low binding capacity and slow kinetics [21]. Electropolymerization scan cycles and scan rates are important factors for the preparation of MIPs, which could affect the thickness and compactness of the polymers. As can be seen, the 20 cycles of scanning (Figure $4 \mathrm{C}$ ) and scan rate of $0.1 \mathrm{Vs}^{-1}$ (Figure $4 \mathrm{D}$ ) are the optimal electropolymerization conditions. The polymers are unstable and could not coat the electrode surface completely when the scan cycles were less than 20. Higher cycles lead to the formation of thicker polymers, which also affect the sensitivity of the sensor. A slower scan rate could form tight polymers, which decrease the number of accessible imprinted sites. However, a higher scan rate could form loose and rough polymers, which could affect the stability and specificity adsorption of the polymers [22].

The incubation time of the MIPs in the analyte solution is another critical factor for the performance of the imprinted sensor. As can be seen from Figure 4E, the peak current increases with increasing incubation time from 30 to $120 \mathrm{~s}$ and then levels off after $120 \mathrm{~s}$. Therefore, an incubation time of $120 \mathrm{~s}$ was selected for the following measurements. 

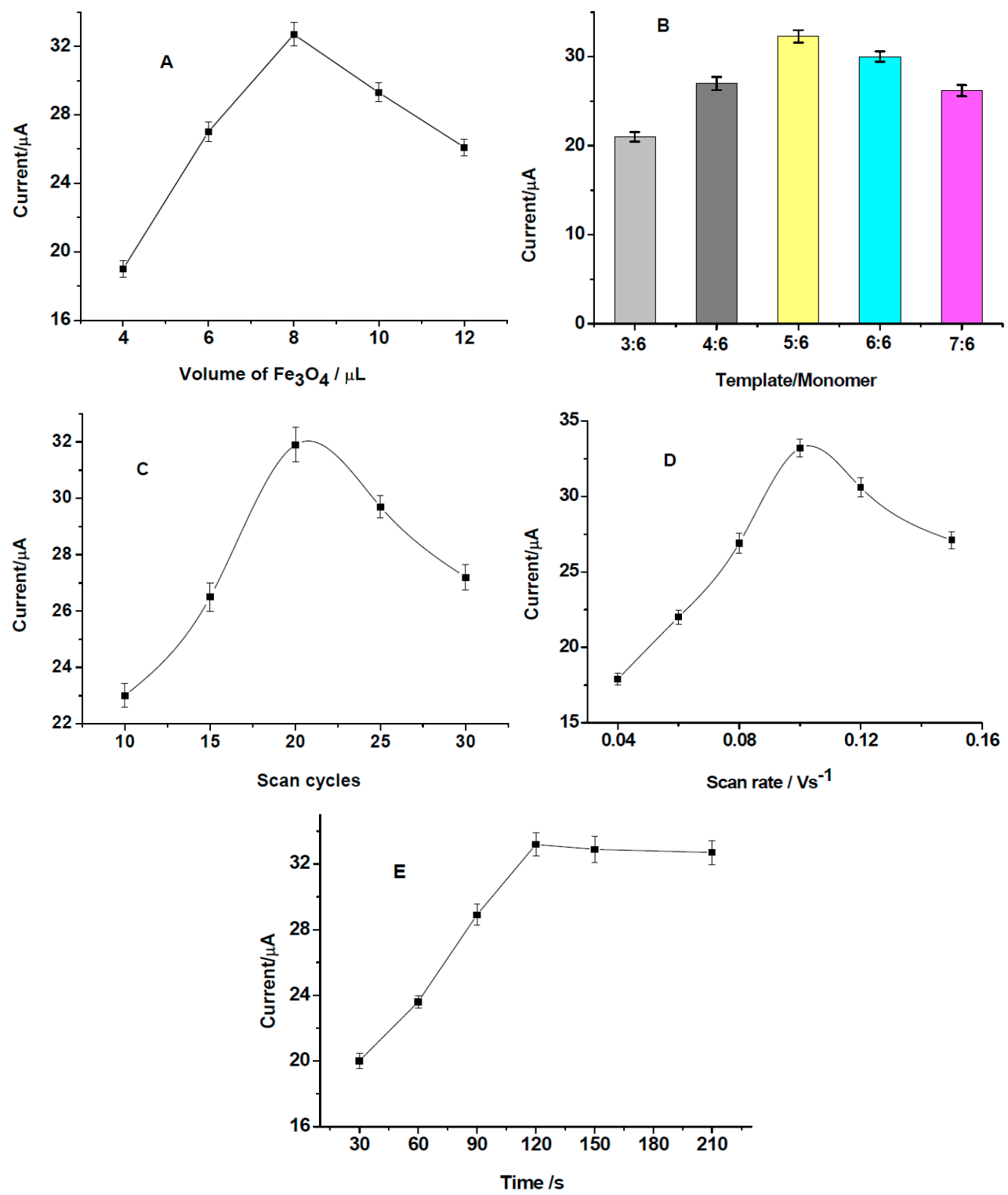

Figure 4. Influences of different preparation conditions on the response of the sensor to $20 \mu \mathrm{M}$ of 2,4-DCP: (A) amount of $\mathrm{Fe}_{3} \mathrm{O}_{4}$ nanoparticles; (B) the ratio of template/monomer; (C) electropolymerization scan cycles; (D) scan rate; (E) incubation time.

\subsection{Determination of $2,4-D C P$}

Square wave voltammetry (SWV) was used for the determination of 2,4-DCP due to its higher current sensitivity and better resolution than cyclic voltammetry. Figure 5 shows the SWVs of $\mathrm{MIPs} / \mathrm{Fe}_{3} \mathrm{O}_{4} / \mathrm{GCE}$ in electrolyte solution containing different concentrations of 2,4-DCP. The oxidation peak currents of 2,4-DCP are proportional to their concentrations in the range from 0.04 to $2.0 \mu \mathrm{M}$, with a detection limit of $0.01 \mu \mathrm{M}$ (inset).According to the IUPAC recommendation [23], the detection limit is determined using 3ó/slope ratio, where ó is the standard deviation of the mean value for 10 determinations of the blank. The linear regression equation can be expressed as $I_{\mathrm{pa}}(\mu \mathrm{A})=2.73+20.5 \mathrm{c}(\mu \mathrm{M})$, with a correlation coefficient $r=0.9994$.

In addition, the determination performance of the sensor fabricated in this work was compared with other electrochemical methods. As shown in Table 1, it is clear that the proposed sensor has a wide linear range and a low detection limit, which makes it suitable for the determination of trace 2,4-DCP. 


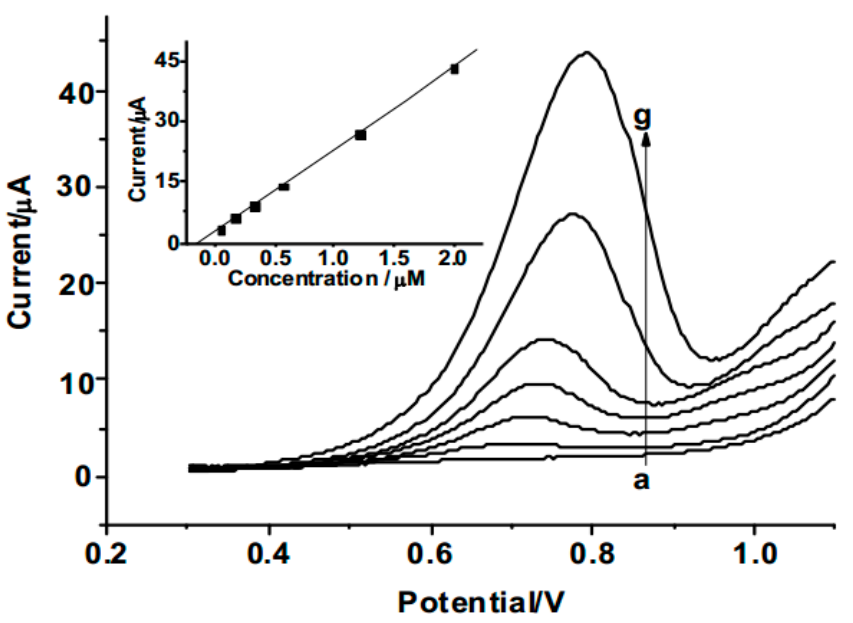

Figure 5. Square wave voltammetry (SWVs) of $\mathrm{MIPs} / \mathrm{Fe}_{3} \mathrm{O}_{4} / \mathrm{GCE}$ in solution containing different concentrations of 2,4-DCP, from a-g: 0, 0.04, 0.16, 0.32, 0.56, 1.2, $2.0 \mu \mathrm{M}$. Inset: plot of peak current versus $2,4-\mathrm{DCP}$ concentration.

Table 1. The determination performance comparison with other electrochemical methods.

\begin{tabular}{cccc}
\hline Modified electrode & Linear range $(\mu \mathbf{M})$ & LOD $(\mu \mathbf{M})$ & References \\
\hline Nafion/MWNTs/GCE & $0.1-100$ & 0.037 & {$[5]$} \\
Tyrosinase/MWNTs/GCE & $2.0-100$ & 0.66 & {$[6]$} \\
Lac/PVA/F108/Au NPs/GCE & $1.0-25.0$ & 0.04 & {$[7]$} \\
Mb-AG/GCE & $12.5-208$ & 2.06 & {$[24]$} \\
$\mathrm{HRP} / \mathrm{MWNTs} / \mathrm{GCE}$ & $1.0-100$ & 0.38 & {$[25]$} \\
$\mathrm{MIPs} / \mathrm{Fe}_{3} \mathrm{O}_{4} / \mathrm{GCE}$ & $0.04-2.0$ & 0.01 & this work \\
\hline
\end{tabular}

MWNTs, multiwalled carbon nanotubues; Lac, laccase; PVA, polyvinyl alcohol; F108, polyethyleneoxidepolyoxypropylene-polyethyleneoxide (PEO-PPO-PEO); Au NPs, gold nanoparticles; MB-AG, Myoglobin and agarose; HRP, horseradish peroxidase.

\subsection{Reproducibility and Stability}

The reproducibility and stability of the proposed sensor were studied. The data results were shown in Table 2. To investigate the reproducibility of the proposed sensor, a series of four sensors prepared in the same manner were tested for the determination of $0.3 \mu \mathrm{M} 2,4$-DCP and the RSD was $2.4 \%$. The stability of the sensor was also studied, when the prepared sensor was stored at room temperature after two weeks, the peak current response retained $93 \%$ of its initial response.

Table 2. Data results of reproducibility and stability.

\begin{tabular}{cccccc}
\hline \multirow{2}{*}{ Items } & \multicolumn{4}{c}{ Current response of sensors $(\mu \mathrm{A})$} & \multirow{2}{*}{ RSD (\%) (n=4) } \\
& Sensor $\mathbf{1}$ & Sensor $\mathbf{2}$ & Sensor $\mathbf{3}$ & Sensor 4 & \multirow{2}{*}{ RS } \\
\hline Reproducibility & 8.79 & 9.55 & 8.46 & 9.23 & 2.4 \\
Stability & 0 day & 3 day & 7 day & 14 day & \\
\hline
\end{tabular}

\subsection{Selectivity Study}

To verify the selectivity of the proposed sensor, hydroquinol, hydroxyphenol, 2-chlorophenol, 2,4,6-trichlorophenol, and pentachlorophenol were selected in the interference experiments. The interference experiments were carried out by detecting the current response of $0.3 \mu \mathrm{M} 2,4-\mathrm{DCP}$ at $\mathrm{MIPs} / \mathrm{Fe}_{3} \mathrm{O}_{4} / \mathrm{GCE}$ in the presence of a 5 -fold concentration of the interference species. As can be seen in Figure 6, the above species did not show obvious interference to the 2,4-DCP detection. 
Moreover, the effect of several ions on the determination of 2,4-DCP was also studied. The results showed that 200-fold concentrations of $\mathrm{Na}^{+}, \mathrm{K}^{+}, \mathrm{Zn}^{2+}, \mathrm{Mg}^{2+}, \mathrm{Al}^{3+}, \mathrm{Ca}^{2+}, \mathrm{Cl}^{-}, \mathrm{NO}_{3}{ }^{-}, \mathrm{SO}_{4}{ }^{2-}$ have no interference on the determination of 2,4-DCP. The results suggested that the proposed sensor has good selectivity for the detection of 2,4-DCP.

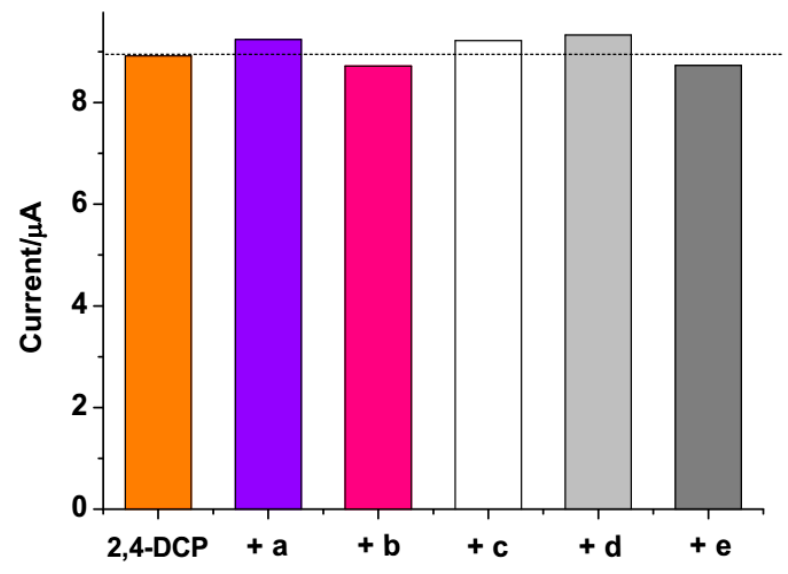

Figure 6. The peak current changes of $0.3 \mu \mathrm{M}$ 2,4-DCP at $\mathrm{MIPs} / \mathrm{Fe}_{3} \mathrm{O}_{4} / \mathrm{GCE}$ with addition of 5-fold concentration of interference species: (a) 2-chlorophenol; (b) hydroxyphenol; (c) pentachlorophenol; (d) 2,4,6-trichlorophenol; (e) hydroquinol.

\subsection{Real Water Sample Analysis}

To investigate the applicability of the proposed sensor for the determination of 2,4-DCP, local river water samples were used for the quantitative analysis. No obvious electrochemical response was found for the water samples. It is assumed that there is no 2,4-DCP in the river sample or the concentration of 2,4-DCP is too low to be detected. Thus, the recovery experiments were performed by adding known concentrations of 2,4-DCP. The data are listed in Table 3. The recoveries range from $94.2 \%$ to $97.5 \%$, which indicate the applicability and reliability of the proposed sensor.

Table 3. Analysis of 2,4-DCP in spiked water samples.

\begin{tabular}{ccccc}
\hline River water & Added $(\mu \mathrm{M})$ & Found $(\mu \mathrm{M})$ & Recovery $(\%)$ & RSD $(\%)(n=3)$ \\
\hline \multirow{3}{*}{ Sample 1} & 0 & Not detected & - & - \\
& 0.16 & 0.153 & 95.6 & 3.9 \\
& 1.2 & 1.17 & 97.5 & 4.2 \\
\hline \multirow{3}{*}{ Sample 2 } & 0 & Not detected & - & - \\
& 0.16 & 0.155 & 96.9 & 3.7 \\
& 1.2 & 1.13 & 94.2 & 3.4 \\
\hline
\end{tabular}

\section{Conclusions}

In this study, a simple and efficient MIPs based electrochemical sensor was prepared by electropolymerization of pyrrole on a $\mathrm{Fe}_{3} \mathrm{O}_{4}$ nanoparticle modified glassy carbon electrode. The influences of different preparation conditions including amount of $\mathrm{Fe}_{3} \mathrm{O}_{4}$ nanoparticles, the ratio of template/monomer, electropolymerization scan cycles and scan rate on the response of the sensor to 2,4-DCP were investigated. This has provided a technique basis for the preparation of other $\mathrm{Fe}_{3} \mathrm{O}_{4}$ nanoparticles based MIPs. Under the optimum preparation conditions, the sensor showed high selectivity and sensitivity, wide linear range, and low detection limit, which makes it a good sensor for the detection of 2,4-DCP. The applicability of the proposed sensor for the determination of 2,4-DCP in real water samples was performed with good recoveries. The proposed sensor represents a new platform for designing electrochemical sensors for environmental pollutants. 
Acknowledgments: This work was supported by the National Natural Science Foundation of China (21303155), the Natural Science Foundation of Jiangsu Province of China (BK20130427), the Industry-university-research Project of Science and Technology Department of Jiangsu Province (BY2014108-03) and the University Natural Science Research Project of Jiangsu Province of China (16KJB550007).

Author Contributions: Benzhi Liu performed the preparation and characterization of molecularly imprinted polymers modified glassy carbon electrode, and also wrote the paper; Hui Cang performed the electrochemical experiments section; Jianxiang Jin performed the detection of 2,4-DCP.

Conflicts of Interest: The authors declare no conflict of interest.

\section{References}

1. Jin, Z.H.; Yu, C.; Wang, X.Y.; Wan, Y.; Li, D.; Lu, G.Z. Liquid phase hydridechlorination of chlorophenols at lower temperature on a novel Pd catalyst. J. Hazard. Mater. 2011, 186, 1726-1732. [CrossRef] [PubMed]

2. Chao, Y.Y.; Tu, Y.M.; Jian, Z.X.; Wang, H.W.; Huang, Y.L. Direct determination of chlorophenols in water samples through ultrasound-assisted hollow fiber liquid-liquid microextraction on-line coupled with high-performance liquid chromatography. J. Chromatogr. A 2013, 1271, 41-49. [CrossRef] [PubMed]

3. Guo, L.; Lee, H.K. Electro-membrane extraction followed by low-density solvent based ultrasound-assisted emulsification microextraction combined with derivatization for determining chlorophenols and analysis by gas chromatography-mass spectrometry. J. Chromatogr. A 2012, 1243, 14-22. [CrossRef] [PubMed]

4. Feng, Q.; Li, H.; Zhang, Z.; Lin, J. Gold nanoparticles for enhanced chemiluminescence and determination of 2,4-dichlorophenol in environmental water samples. Analyst 2011, 136, 2156-2160. [CrossRef] [PubMed]

5. Arribas, A.S.; Moreno, M.; Bermejo, E.; Pérez, J.A.; Román, V.; Zapar-diel, A.; Chicharro, M. Application of carbon nanotube-modified electrodes as electrochemical sensors for the continuous monitoring of 2,4-dichlorophenol. Electroanalysis 2011, 23, 237-244. [CrossRef]

6. Kong, L.M.; Huang, S.S.; Yue, Z.L.; Peng, B.; Li, M.Y.; Zhang, J. Sensitive mediator-free tyrosinase biosensor for the determination of 2,4-dichlorophenol. Microchim. Acta 2009, 165, 203-209. [CrossRef]

7. Liu, J.; Niu, J.F.; Yin, L.F.; Jiang, F. In situ encapsulation of laccase in nanofibers by electrospinning for development of enzyme biosensors for chlorophenol monitoring. Analyst 2011, 136, 4802-4808. [CrossRef] [PubMed]

8. Xu, Q.; Li, X.J.; Zhou, Y.E.; Wei, H.P.; Hu, X.Y.; Wang, Y.; Yang, Z.J. An enzymatic amplified system for the detection of 2,4-dichlorophenol based on graphene membrane modified electrode. Anal. Methods 2012, 4 , 3429-3435. [CrossRef]

9. Reddy, S.M.; Sette, G.; Phan, Q. Electrochemical probing of selective haemoglobin binding in hydrogel-based molecularly imprinted polymers. Electrochim. Acta 2011, 56, 9203-9208. [CrossRef]

10. Li, J.; Chen, Z.; Li, Y. A strategy for constructing sensitive and renewable molecularly imprinted electrochemical sensors for melamine detection. Anal. Chim. Acta 2011, 706, 255-260. [CrossRef] [PubMed]

11. Zhong, M.; Teng, Y.; Pang, S.; Yan, L.; Kan, X. Pyrrole-phenylboronicacid: A novel monomer for dopamine recognition and detection based on imprinted electrochemical sensor. Biosens. Bioelectron. 2015, 64, $212-218$. [CrossRef] [PubMed]

12. Sharma, P.S.; Pietrzyk-Le, A.; Souza, F.D.; Kutner, W. Electrochemically synthesized polymers in molecular imprinting for chemical sensing. Anal. Bioanal. Chem. 2012, 402, 3177-3204. [CrossRef] [PubMed]

13. Xue, C.; Han, Q.; Wang, Y.; Wu, J.; Wen, T.; Wang, R.; Hong, J.; Zhou, X.; Jiang, H. Amperometric detection of dopamine in human serumby electrochemical sensor based on gold nanoparticles doped molecularly imprinted polymers. Biosens. Bioelectron. 2013, 49, 199-203. [CrossRef] [PubMed]

14. Huang, Y.; Wang, L.; Sun, X. Sandwich-structured graphene@ $\mathrm{Fe}_{3} \mathrm{O}_{4} @$ carbon nanocomposites with enhanced electromagnetic absorption properties. Mater. Lett. 2015, 144, 26-29. [CrossRef]

15. Xing, Y.; Jin, Y.Y.; Si, J.C.; Peng, M.L.; Wang, X.F.; Chen, C.; Cui, Y.L. Controllable synthesis and characterization of $\mathrm{Fe}_{3} \mathrm{O}_{4} / \mathrm{Au}$ composite nanoparticles. J. Magn. Magn. Mater. 2015, 380, 150-156. [CrossRef]

16. Zhang, C.; Si, S.; Yang, Z. A highly selective photoelectrochemical biosensor for uric acid based on core-shell $\mathrm{Fe}_{3} \mathrm{O}_{4} @ \mathrm{C}$ nanoparticle and molecularly imprinted $\mathrm{TiO}_{2}$. Biosens. Bioelectron. 2015, 65, 115-120. [CrossRef] [PubMed]

17. Xing, X.; Liu, S.; Yu, J.; Lian, W.; Huang, J. Electrochemical sensor based on molecularly imprinted film at polypyrrole-sulfonatedgraphene/hyaluronic acid-multiwalled carbon nanotubes modified electrode for determination of tryptamine. Biosens. Bioelectron. 2012, 31, 277-283. [CrossRef] [PubMed] 
18. Ramanavicius, A.; Ramanaviciene, A.; Malinauskas, A. Electrochemical sensors based on conducting polymer-polypyrrole. Electrochim. Acta 2006, 51, 6025-6037. [CrossRef]

19. Kan, X.; Zhou, H.; Li, C.; Zhu, A.; Xing, Z.; Zhao, Z. Imprinted electrochemical sensor for dopamine recognition and determination based on a carbon nanotube/polypyrrolefilm. Electrochim. Acta 2012, 63, 69-75. [CrossRef]

20. Qian, T.; Yu, C.; Zhou, X.; Ma, P.; Wu, S.; Xu, L.; Shen, J. Ultrasensitive dopamine sensor based on novel molecularly imprinted polypyrrole coated carbon nanotubes. Biosens. Bioelectron. 2014, 58, 237-241. [CrossRef] [PubMed]

21. Kong, L.J.; Pan, M.F.; Fang, G.Z.; He, X.L.; Yang, Y.K.; Dai, J.; Wang, S. Molecularly imprinted quartz crystal microbalance sensor based on poly(o-aminothiophenol) membrane and Au nanoparticles for ractopamine determination. Biosens. Bioelectron. 2014, 51, 286-292. [CrossRef] [PubMed]

22. Gong, J.L.; Gong, F.C.; Zeng, G.M.; Shen, G.L.; Yu, R.Q. A novel electrosynthesized polymer applied to molecular imprinting technology. Talanta 2003, 61, 447-453. [CrossRef]

23. Analytical Methods Committee. Recommendations for the definition estimation and use of the detection limit. Analyst 1987, 112, 199-204.

24. Sun, Y.L.; Wang, L.P.; Liu, H.H. Myoglobin functioning as cytochrome P450 for biosensing of 2,4-dichlorophenol. Anal. Methods 2012, 4, 3358-3363. [CrossRef]

25. Huang, S.S.; Qu, Y.X.; Li, R.N.; Shen, J.; Zhu, L.W. Biosensor based on horseradish peroxidase modified carbon nanotubes for determination of 2,4-dichlorophenol. Microchim. Acta 2008, 162, 261-268. [CrossRef]

(C) 2016 by the authors; licensee MDPI, Basel, Switzerland. This article is an open access article distributed under the terms and conditions of the Creative Commons Attribution (CC-BY) license (http:/ / creativecommons.org/licenses/by/4.0/). 